\title{
TANDEM, AUTOAVALIAÇÃO E A AUTONOMIA NA APRENDIZAGEM DE LÍNGUAS ESTRANGEIRAS
}

\section{TANDEM, SELF-EVALUATION AND THE AUTONOMY IN LEARNING FOREIGN LANGUAGES}

\author{
Larissa Paula Tirloni ${ }^{*}$ \\ Valdilena Rammé
}

\section{RESUMO}

A implementação da ferramenta tandem no processo de ensino-aprendizagem de Língua Estrangeira ou Adicional (LE/LA) proporciona contextos reais de interação em que as responsabilidades são compartilhadas entre os alunos: ora aprendizes, ora mestres. Nesses casos, a autonomia e a reciprocidade possibilitam reunir presencialmente e virtualmente estudantes de idiomas de distintas culturas ampliando o conteúdo aprendido em sala e os horizontes profissionais e culturais de acordo com objetivos individuais. Esse pedalar na mesma direção implica uma mútua colaboração, assim como funciona em qualquer outra relação entre pessoas que almejam beneficiar-se de uma parceria. A responsabilidade conferida aos parceiros tandem impõe-lhes e concede-lhes a oportunidade de definirem seus próprios objetivos e de criarem estratégias para alcançar suas metas (BRAMMERTS \& CALVET, 2003, p. 33). Assim, a autoavaliação torna-se primordial para um exercício crítico e constante da aprendizagem. Por esse viés, este trabalho pretende analisar a relevância de atividades de autoavaliação no processo de ensino-aprendizagem de línguas próximas (português e espanhol), com foco nas estratégias desenvolvidas pelos aprendizes para um maior aproveitamento dessa ferramenta didática. Para tal projeto, investigamos os aportes teóricos e fichas de autoavaliação desenvolvidos nesse modelo pedagógico (MESQUITA, 2008; CAVALARI, 2009; FURTOSO, 2011). Os dados foram gerados através do acompanhamento meticuloso de sessões de tandem e teletandem na UNILA e na UNIOESTE, da elaboração e aplicação de questionários e grades de (auto)avaliação, bem como de sessões de Conversa Reflexiva com os pares. Os resultados preliminares apontam para o desenvolvimento, em alunos e professores, da real consciência de que o aprendiz de LE é também agente de seu aprendizado. Essa mudança de concepção leva, consequentemente, alunos e professores a reexaminarem seus papéis; ação que provoca uma maior participação dos alunos no processo de ensino-aprendizagem-avaliação dos cursos de LE. Todo esse processo resulta, enfim, em um maior aproveitamento do estudante.

Palavras-chave: tandem; (auto) avaliação; autonomia na aprendizagem.

\footnotetext{
* Universidade Estadual do Oeste do Paraná, Unioeste, Cascavel (PR), Brasil. larissatirloni@hotmail. $\underline{\mathrm{com}_{i}}$ Universidade Federal da Integração Latino-Aamericana, UNILA, Foz do Iguaçu (PR), Brasil. val.ramme@gmail.com
} 


\section{ABSTRACT}

The implementation of tandem in foreign languages teaching-learning processes provides real contexts of interaction where responsibilities are shared among students: sometimes they are the apprentices, sometimes the masters. In such cases, autonomy and reciprocity make possible the meeting of students from different cultures-languages expanding the content learned in the classroom and the professional and cultural horizons according to individual goals. This riding in the same direction implies a mutual collaboration, as well as it happens in any relationship between people that aim to benefit from a partnership. The responsibility given to tandem partners requires and gives them the opportunity to define their own goals and create strategies to achieve their own objectives (BRAMMERTS \& CALVET, 2003, p. 33). Thus, self-assessment becomes paramount for a critical and constant practice of learning. By this bias, this study aims to examine the relevance of selfassessment activities in the processes of teaching and learning similar languages (Portuguese and Spanish), focusing on strategies developed by the learners to make better use of this teaching-learning tool. Therefore, we investigate the theoretical contributions and selfassessment forms developed inside this pedagogical model (MOSQUE, 2008; CAVALRY, 2009; FURTOSO, 2011). Data was generated through the monitoring of tandem and teletandem sessions in UNILA and UNIOESTE, the development and implementation of surveys and grids of (self)evaluation, as well as Reflective Conversation sessions with the peers. Preliminary results point to the development, in students and teachers, of the real understanding that the LE apprentice is also an agent of his/her learning process. This change in conception consequently leads students and teachers to re-examine their roles, and such action, in time, promotes a greater participation of students in the teachinglearning-evaluation processes developed in foreign language courses. This whole practice results finally in a higher student achievement.

Keywords: tandem; (self) evaluation; autonomy in learning.

\section{INTRODUÇÃO}

O presente artigo é fruto das reflexões geradas dentro de uma pesquisa-ação dirigida por duas professoras de Português Língua Estrangeira/Adicional (PLE/ PLA) e de Espanhol Língua Estrangeira (ELE). Tal projeto nasceu da necessidade de se pensar e debater sobre a avaliação das habilidades orais em classe de língua estrangeira/adicional e da tentativa de promoção de um ambiente que propiciasse o amplo desenvolvimento dessas habilidades, ou seja, a implementação da ferramenta de ensino-aprendizagem tandem nas aulas de línguas estrangeiras.

O tandem é uma forma de estudar e aprender línguas largamente difundida ao redor do mundo, potencializada pela expansão do acesso às novas tecnologias por parte de grande número de aprendizes de línguas em muitos e distintos países. Em síntese, trata-se de uma parceria entre dois aprendizes de línguas estrangeiras na qual cada estudante se compromete a ensinar sua língua-cultura ao outro, em troca de aprender mais sobre a língua-cultura do colega. 
No Brasil, diferentes projetos já oferecem o tandem como recurso complementar às aulas de línguas regulares. Podemos citar, entre os casos de maior destaque, o Projeto Teletandem Brasil', conduzido pelo professor João A. Telles na Universidade Estadual Paulista de Assis (UNESP-Assis), e o projeto Núcleo Tandem Celin-UFPR2, dirigido pelas professoras Bruna Ruano e Gabriela Diniz na Universidade Federal do Paraná. Nossa experiência, contudo, ainda difere dessas últimas, pois consiste na inserção do tandem como uma atividade integrada às aulas de PLE/ELE, conforme definição abaixo:

(...) a principal diferença entre o tandem integrado e o tandem livre [é] a natureza de seus participantes: no tandem livre, os participantes podem ser alheios à área de Letras e, consequentemente, não possuir o conhecimento técnico ou teórico de teorias linguísticas ou didáticas. No outro caso, pelo menos um dos participantes, no que se inclui o monitor ou professor responsável pelas sessões de tandem, tem experiência pedagógica.

No tandem integrado, então, além do maior controle didático-pedagógico, espera-se a incorporação de atividades de formação linguística e cultural que se conectem aos conteúdos trabalhados em sala e aos objetivos do aluno com aquele curso. Há a possibilidade, nesses contextos, de se usar o tandem como ferramenta avaliadora do processo de aprendizagem.

(RAMMÉ, 2014)

Nessa perspectiva, partindo do objetivo de criar contextos de prática autêntica das habilidades orais - complexas e efêmeras -, dadas as dificuldades enfrentadas em sala, nos pareceu latente a necessidade de pensarmos igualmente a avaliação de forma contínua e com destaque para as estratégias utilizadas pelos pares de aprendizes para atingirem seus objetivos de aprendizagem e desempenho na língua alvo.

Com base nos aportes teóricos e fichas de avaliação desenvolvidos no modelo tandem de ensino-aprendizagem (MESQUITA, 2008; CAVALARI, 2009; FURTOSO, 2011), este trabalho pretende refletir, portanto, sobre a pertinência da (auto)avaliação potencializando seu caráter formativo-processual (DEMO, 1996; SCARAMUCCI, 1999; BRINDLEY, 2001) considerando as perspectivas de aprendizes universitários de espanhol e português como língua estrangeira (ELE/ PLE). Tais alunos participaram dos projetos de extensão "Tandem na UNIOESTE: hablantes sin frontera" (Universidade Estadual do Oeste do Paraná) e "TANDEM: Português e Espanhol pedalando juntos" (na Universidade Federal da Integração Latino-Americana - UNILA) no decorrer de 2014. É válido ressaltar que os projetos utilizaram diferentes modalidades de tandem: os aprendizes de PLE e 
parte dos de ELE estão inseridos no contexto da Língua Adicional e/ou convivem com falantes nativos; nesse caso o tandem realizado foi o presencial (face a face). Em contrapartida, os aprendizes de ELE da UNIOESTE realizaram o tandem em ambiente virtual, ou seja, o teletandem.

Assim, iniciamos este artigo discutindo os contextos das universidades envolvidas e a internacionalização destas a partir da democratização das ferramentas de comunicação. Em seguida, apresentamos uma breve reflexão teórica acerca da autonomia na aprendizagem e sua relação intrínseca com o tandem e com a formação de um aprendiz mais consciente da importância da avaliação formativa. Posteriormente, nos debruçamos mais cuidadosamente sobre distintos conceitos e tipos de avaliação, aproximando as teorias revisadas da prática do tandem. Finalmente, expomos os dados gerados a partir de questionários, grades de (auto) avaliação e conversas reflexivas para discussão dos resultados obtidos em nível micro e macro do processo de pesquisa. Nas considerações finais, debatemos possíveis direcionamentos e sugestões para a continuidade desta pesquisa-ação.

\section{NOSSO CONTEXTO}

\subsection{A democratização das ferramentas de comunicação e a UNIOESTE}

Quando mencionamos que o tandem potencializa a autonomia na construção da aprendizagem, é preciso destacar a importante contribuição das novas tecnologias para o desenvolvimento cognitivo em novos espaços de aprendizagem. Ademais, se faz necessário reconhecer a importância da democratização e da aplicabilidade das ferramentas de comunicação. Estas proporcionam novos olhares através de recursos dinâmicos que permitem aproximações antes inimagináveis, busca e seleção de informações, curiosidade, mesclagem de sons, imagens e textos.

Com o intuito de inserir nossos alunos em um processo de aprendizagem interativo e atrativo, centrado no aluno, aumentando a sua motivação de aprender, conhecer e melhorar sua oralidade na LE, o teletandem (tandem via internet e outros suportes digitais) se mostrou, de fato, um método eficaz para alcançarmos nossos objetivos.

Dessa forma, na Universidade Estadual do Oeste do Paraná - UNIOESTE, o projeto "Tandem na UNIOESTE: hablantes sin frontera" reuniu cerca de vinte aprendizes e nativos de língua espanhola e língua portuguesa que desejavam ampliar seus conhecimentos em LE. Os encontros ocorreram entre alunos brasileiros de 
Letras e Hotelaria da UNIOESTE e alunos mexicanos do Centro de Enseñanza de Lenguas Extranjeras da Universidade Nacional Autônoma do México (CELE - UNAM) através de correio eletrônico e do Skype, tendo como tópico temas variados e estabelecidos pelos próprios estudantes de acordo com suas necessidades e objetivos.

Durante o semestre letivo, parte das sessões de teletandem foi monitorada e ocorreu no laboratório de informática das respectivas Universidades, organizandose da seguinte maneira: em média 1 hora de conversa por semana - 20min em português, 20min em espanhol e, nos últimos 10min, o feedback. As demais aconteceram constantemente no dia a dia dos participantes fora e dentro da Universidade. Para o controle e posterior discussão e avaliação, após o término de cada reunião monitorada, os estudantes preenchiam seus diários de aprendizagem e mantinham conversas reflexivas com suas respectivas professoras mediadoras.

Por outro lado, o projeto desenvolvido concomitantemente na UNILA desenvolveu-se em um contexto diferente: alunos brasileiros e hispano-falantes encontravam-se no mesmo espaço físico, i.e., na mesma universidade. Nos ateremos então, na próxima seção, a observar como esse projeto foi desenvolvido. Para aqueles que desejam conhecê-lo mais detalhadamente, referimos o site do projeto, www.tandemunila.com.br e um relato de experiência publicado na revista Experiência ${ }^{3}$ em julho/2015.

\subsection{A internacionalização de nossas Universidades e a UNILA}

É fato que um grande passo para que as universidades brasileiras figurem entre as melhores do mundo passa pela sua internacionalização. A internacionalização de uma universidade, por sua vez, implica sua habilidade em criar parcerias bem sucedidas de pesquisa científica e inovação tecnológica. Essas parcerias, desse modo, dependem de um quesito central: a língua. É ela que permitirá a circulação de estudantes e pesquisadores estrangeiros em nossas universidades, a possibilidade de viagem de nossos professores, alunos e pesquisadores para outras instituições e a troca e livre acesso aos conhecimentos produzidos através de cooperações solidárias.

No Brasil, a CAPES - Coordenação de Aperfeiçoamento de Pessoal de Nível Superior - vem dirigindo, na última década, planos e estratégias de internacionalização de nossas universidades. Nesse contexto, a UNILA se coloca

3 Para acessar a revista, remetemos o leitor interessado ao site: http://www.ufsm.br/experiencia 
como uma Universidade Federal brasileira que já nasceu internacional. No PDIUNILA, ambiciona-se que 50\% dos discentes sejam originários de outros países latino-americanos. Consequentemente, essa Universidade já nasce bilíngue: português e espanhol foram os idiomas escolhidos para a instrução e divulgação de conhecimento científico dessa IES. Ainda de acordo com o PDI-UNILA, o bilinguismo permitiria a nossa efetiva participação nos diálogos e processos interculturais locais, regionais e internacionais.

Dessa forma, para alcançar o bilinguismo, os alunos de todos os cursos da UNILA frequentam durante os três primeiros semestres cursos de línguas com a carga horária de $6 \mathrm{~h}$ a $8 \mathrm{~h} / \mathrm{semanais.} \mathrm{As} \mathrm{aulas} \mathrm{de} \mathrm{PLA} \mathrm{e} \mathrm{ELA} \mathrm{acontecem} \mathrm{ao} \mathrm{mesmo}$ tempo: enquanto os discentes brasileiros aprendem espanhol, seus colegas hispanofalantes fazem aulas de português na sala ao lado. Essa conjuntura permite que os professores de PLA e ELA possam organizar sessões de tandem entre suas turmas de maneira extremamente prática. Assim, uma vez por semana, durante a hora final de uma das aulas, as duas turmas podem se reunir (no jardim, na cantina, na sala...) para a sessão de tandem, na qual os brasileiros ajudarão seus colegas a aperfeiçoarem seu português, e na meia-hora restante, os companheiros hispanofalantes auxiliarão os brasileiros na sua aprendizagem do espanhol.

É, portanto, inseridos nesses dois contextos distintos que se encontram os sujeitos desta pesquisa. Ao todo, aproximadamente 200 alunos de PLA e ELA fizeram tandem no segundo semestre letivo de 2014 na UNILA. Destes, 19 aceitaram responder a um questionário online sobre avaliação. Todos os outros, contudo, participaram das conversas reflexivas conduzidas pelos professores nas aulas subsequentes ao tandem. Antes de abordarmos a metodologia empregada, no entanto, faremos uma breve discussão sobre os diferentes conceitos e formas de avaliação que guiarão o nosso debate.

\section{AUTONOMIA NA APRENDIZAGEM}

Em Pedagogia da Autonomia (1996), o educador Paulo Freire confere à autonomia liberdade a possibilidade de construção e reconstrução de conceitos. Ao partir de uma educação emancipadora e transformadora, pensadores como Freire nos auxiliam a refletir e a reanalisar os papéis desempenhados por professores e alunos, na constante busca por melhoria e diversificação das práticas docentes; e, consequentemente, a conscientizar-nos da necessidade de promover uma maior participação dos alunos no seu processo de ensino-aprendizagem. 
Uma rápida consulta às pesquisas atuais em Linguística Aplicada revela que a autonomia na aprendizagem é um tema recorrente. Henri Holec (1981), um dos precursores em conceitualizar a autonomia no ensino-aprendizagem de língua estrangeira, define essa ideia como "a capacidade de se responsabilizar pela própria aprendizagem". Nessa perspectiva, é o estudante que deve determinar seus objetivos, conteúdos a serem revisitados e/ou estudados; que atua na seleção de métodos e técnicas, além de monitorar o processo de aquisição da LE e de participar ativamente na avaliação do que foi/está sendo/será aprendido (HOLEC, 1981).

De maneira análoga, Little (1991, p.21) descreve a autonomia como a "capacidade de auto-direção no planejamento, no monitoramento e avaliação de atividades de aprendizagem". Tendo em vista que a prática de um aprendizado autônomo demanda tomadas de decisão, é latente a necessidade de independência por parte do estudante e também de orientação e diálogo entre professor e aluno, criando-se, assim, um espaço de formação para a avaliação do/pelo aprendiz.

\subsection{Autonomia no tandem}

No percuciente entender de Dickinson (1987, p. 03), autonomia é a "responsabilidade total pela tomada e implementação de todas as decisões a respeito da própria aprendizagem". Por esse viés, o estudante, ao constatar que está no controle de sua aprendizagem, é forçado a descobrir mecanismos de verificação de aprendizagem e, consequentemente, a pensar em avaliação, na relação existente entre ele e seu objeto de reflexão.

Em tal contexto, a ferramenta tandem, para além de uma ferramenta de desenvolvimento da habilidade oral, surge como prática de conscientização e de promoção da autonomia, posto que nosso aluno encontra-se em uma situação real de uso da língua, não se limitando aos espaços tradicionais de prática e onde a monitoração do professor é bastante (ou totalmente) limitada. Leffa (2003, p. 15) destaca que "a aprendizagem que realmente interessa, aquela que não é apenas reprodução do que já existe, mas criação de algo novo, de progresso e avanço, só é possível com autonomia". No tandem, a autonomia concedida aos estudantes, autonomia esta que não se relaciona à ausência de regras e limites, como referencia Dickinson (1994), força o aluno a se auto-avaliar e a avaliar seus pares, já que o estudante se conscientiza de que seu esforço é essencial para a melhoria da aprendizagem de ambos.

Ao envolver-se integralmente no processo de avaliação e autoavaliação, o estudante, retomando as palavras de Paulo Freire, ao ter uma atitude e postura 
diferente, pode construir e reconstruir criticamente seu conhecimento e auxiliar no desenvolvimento de seu/sua companheiro(a), revisitando o processo de aprendizagem na busca de desenvolver estratégias para aprimorar seu desempenho em LE.

É possível concluir, portanto, que é de suma importância proporcionar o contato com práticas de ensino-aprendizagem de língua estrangeira que fomentem a autonomia, seguidas de espaços de reflexão e avaliação; o que verificaremos com os resultados preliminares dos questionários e conversas reflexivas. Ser autônomo implica ser crítico, decidir conscientemente seus objetivos e quais caminhos deve percorrer para atingi-los.

Sendo assim, o tandem potencializa uma aprendizagem autônoma que integra conhecimentos linguísticos, sociais, culturais e habilidades adquiridas em contextos de sala de aula e em contextos de comunicação autêntica. Em vista disso, percebemos o tandem como um ambiente colaborativo e reflexivo, no qual os estudantes são os protagonistas de sua aprendizagem, sendo capazes de desenvolver a habilidade de avaliar sua própria progressão na aprendizagem.

\section{A AVALIAÇÃO}

Dentre as múltiplas tarefas de um(a) professor(a), talvez a mais árdua seja a de avaliar. Tanto mais, porque uma parte do que acaba sendo avaliado é a capacidade de um(a) professora(a) auxiliar seus alunos de alcançarem seus objetivos de aprendizagem. Além disso, em se tratando do ensino-aprendizagem de línguas, em diversas circunstâncias o ato de avaliar extrapola as paredes das salas de aula e centros educacionais, ele tem o papel de certificar a capacidade de um determinado aprendiz de "agir" na língua alvo, em um determinado nível de competência, com o objetivo de "tornar público o que parece ter sido aprendido pelos alunos" (FERNANDES, 2008, p.258). Dentro deste último cenário, podemos citar os vários certificados de línguas conhecidos mundialmente, como o TOEFL e o Cambridge Certificate para o inglês, o DELF/DALF, para o francês, o CELU e o DELE para o espanhol, ou o Celpe-Bras, para o português.

Em ambas as situações, contudo, inserido em um curso de línguas ou como uma certificação de proficiência, a avaliação não pode ser tomada como uma atividade trivial. Embora uma teoria da avaliação seja almejada por diversos autores (BLOOM et. al., 1971; FERNANDES, 2008; HARLEN, 2005, 2006; DICKINS \& GERMAINE, 2014, entre outros) a complexidade dessa tarefa ainda nos reserva 
um longo caminho de pesquisa e discussão. Todavia, há claramente, no momento, uma preocupação em distinguir o que podemos chamar de avaliação formativa versus avaliação somativa, ou ainda, nas palavras retomadas por Fernandes (2008), avaliação para as aprendizagens vs. avaliação das aprendizagens, respectivamente. Tentaremos revisar, brevemente, os pressupostos de ambas as abordagens.

\subsection{A avaliação somativa}

É manifesto que alguns exames de proficiência focalizam a testagem de habilidades - dividindo seus testes em partes autônomas: compreensão oral e escrita, expressão oral e escrita, gramática -, granulando seus distintos níveis de certificação de acordo com o conhecimento que o postulante demonstra ou sua competência em compreender ou se expressar em situações de díspar complexidade linguística no momento da avaliação. Outros exames, ao mesmo tempo, preferem focar na verificação da capacidade de o postulante usar a língua para completar uma determinada tarefa em distintos graus de complexidade.

Em todos os casos, entretanto, para a concessão de um certificado, o que se considera é o resultado de todo o processo de aprendizagem do indivíduo, ou seja, sua capacidade atual (no momento do teste) de desempenhar as tarefas esperadas, ou demonstrar o conhecimento necessário em língua estrangeira para um determinado nível. Poderíamos dizer, então, que o foco dessas avaliações está no ponto final do processo de aprendizagem, i.e., no produto da aprendizagem do examinando.

Apesar de bastante relevantes para situações de avaliação em que a medida do desempenho do candidato, ou sua classificação em relação a outros, seja necessária, a abordagem somativa ainda é incorporada amplamente e quase exclusivamente nas práticas docentes de professores brasileiros (CHUEIRI, 2008). E embora não devesse figurar como a única ou mais relevante forma de avaliar, Rolim (1998, p.10) revela que "na prática, em contextos de ensino de línguas em geral, (...) [há uma] falta de compreensão da maioria dos professores a respeito da função educativa da avaliação; consequentemente, a prática avaliativa fica reduzida a uma mera verificação da quantidade de erros e acertos produzidos pelos alunos".

A despeito deste cenário negativo, contudo, há claramente nas últimas décadas, uma crescente disposição a se, pelo menos, discutir o caráter formativo da avaliação (PERRENOUD \& THURLER, 2002; OTSUKA \& ROCHA, 2002; FERNANDES, 2006; SANTOS, 2006; OLIVEIRA, 2007; PACHECO, 2012; entre outros). Assim, abordaremos rapidamente algumas ideias centrais desta discussão na próxima seção. 


\subsection{A avaliação formativa}

Em oposição à avaliação pós-aprendizagem, focada no produto, a avaliação formativa "está associada a formas de regulação e de auto-regulação que influenciam de forma imediata os processos de ensino e aprendizagem" (FERNANDES, 2008, p.358). Para Fernandes, tal concepção repousa, majoritariamente, no caráter qualitativo que o ato de avaliar pode assumir: enquanto a avaliação somativa apresenta um caráter quantitativo, a avaliação formativa se preocupa com a qualidade dos julgamentos oferecidos pelo professor:

(...) um processo importante é o de regular a qualidade do trabalho que está a ser desenvolvido, utilizando, nomeadamente, um conjunto de recursos cognitivos e metacognitivos que ajudem a eliminar qualquer eventual distância entre as aprendizagens reais e as aprendizagens previstas ou propostas. De facto, tal como refere Biggs (1998), só poderemos dizer que uma avaliação é realmente formativa se, através dela, os alunos se consciencializarem das eventuais diferenças entre o seu estado presente e o estado que se deve alcançar e do que é necessário fazer para as reduzir ou mesmo eliminar. (FERNANDES, 2008, p.356)

Como é manifesto, essa visão da avaliação leva em conta duas ideias fundamentais: primeiramente, a ideia de que não compete exclusivamente ao professor a função de avaliar a aprendizagem dos alunos, estes também devem assumir a responsabilidade de julgar seu próprio desempenho e progresso. Em segundo lugar, que a avaliação é um instrumento poderoso para o controle da qualidade da atividade de ensino, auxiliando o professor/tutor/aprendiz no balizamento de suas lições, na crítica e eventual melhoria de suas aulas, possibilitando mudanças nas abordagens, nos métodos, nos objetivos de ensino-aprendizagem, etc.

Esses dois pilares são mantidos, por sua vez, pelo caráter interativo que essa maneira de avaliar pressupõe. Para Fernandes (2008, p.354), "a avaliação só pode assumir a sua natureza formativa num contexto interactivo". Nesse sentido, o autor sistematiza algumas características que considera fundamentais:

1. A avaliação é deliberadamente organizada em estreita relação com um feedback inteligente, diversificado, bem distribuído, frequente e de elevada qualidade tendo em vista apoiar e orientar os alunos no processo de aprendizagem.

2. O feedback é importante para activar os processos cognitivos e metacognitivos dos alunos, que, por sua vez, regulam e controlam os processos de aprendizagem, assim como para melhorar a sua motivação e autoestima.

3. A natureza da interacção e da comunicação entre professores e alunos é central porque os professores têm que estabelecer pontes entre o que se considera ser 
importante aprender e o complexo mundo dos alunos (por exemplo, o que eles são, o que sabem, como pensam, como aprendem, o que sentem e como sentem).

4. Os alunos são deliberada, activa e sistematicamente envolvidos no processo do ensino-aprendizagem, responsabilizando-se pelas suas aprendizagens e tendo amplas oportunidades para elaborarem as suas respostas e para partilharem o que e como compreenderam.

(FERNANDES, 2008, p.356)

Finalmente, Fernandes (2008) destaca os resultados da investigação empírica de Black \& Wiliam (1998):

1. Os alunos que frequentam salas de aula em que a avaliação é essencialmente de natureza formativa aprendem significativamente mais e melhor do que os alunos que frequentam aulas cuja avaliação é sobretudo somativa.

2. Os alunos que mais se beneficiam da utilização deliberada e sistemática da avaliação formativa são os alunos que têm mais dificuldades de aprendizagem. É levando em consideração a discussão da relevância e necessidade de incorporação de avaliações formativas a nossa prática docente que nos questionamos sobre de que maneira o tandem poderia auxiliar na avaliação dentro de aulas de língua estrangeira. (BLACK \& WILIAM, 1998 apud FERNANDES, 2008, p.364)

Retomando nossa questão inicial, ou seja, o grande desafio que advinha de nossa necessidade de melhorar a qualidade da avaliação e prática das habilidades orais e de comunicação de nossos alunos, à luz destas revelações e teorias, nos perguntamos de que forma poderíamos inserir a avaliação formativa em nosso trabalho. Assim, delineamos uma pesquisa-ação que se concentrasse na verificação da sensibilização à avaliação formativa através do tandem.

\subsection{A avaliação nas sessões de tandem}

É inegável, como já mencionamos, que a avaliação das habilidades orais é razão de grande inquietação. Diferentemente de uma produção escrita, duradoura e material, a produção oral dos aprendizes de línguas, por suas propriedades efêmeras e impalpáveis, corre o risco, muitas vezes, de ser avaliada de forma altamente subjetiva, na qual questões como o grau de extroversão de um determinado aluno podem interferir nas consequências de sua ação ou no resultado do julgamento. 
Nesse sentido, há pesquisadores e professores que se dedicam a investigar minuciosamente as situações de avaliação oral na busca de critérios e balizadores que possam minimizar as interferências da subjetividade. Laia (2010), por exemplo, desenvolve sua dissertação discutindo e analisando grelhas de avaliação oral quantitativas para o ensino de Francês no sistema escolar português. A pesquisadora foca sua empresa na busca de uma forma de avaliação que pudesse excluir o máximo de interferência subjetiva no momento de avaliar a performance oral dos aprendizes de língua estrangeira.

Todavia, como temos debatido, apesar de tal empresa ser bastante relevante para a discussão da avaliação como ferramenta certificativa, ela não abarca, necessariamente, todos os contextos de sala de aula. Principalmente porque, na concepção de avaliação buscada pelas pesquisadoras e autoras deste artigo, o problema central da avaliação no ensino de línguas não está ligado à interferência da subjetividade do professor no momento da avaliação, mas sim à concepção da avaliação como um procedimento que foca na quantidade de no resultado da aprendizagem, em vez de estar focado no processo e na qualidade desta.

Dessa forma, é importante ressaltar mais uma vez, que foi exatamente por suas características interativas, reflexivas, críticas e autônomas, que decidimos incorporar o tandem como ferramenta de prática oral e de avaliação formativa em nossas classes de língua estrangeira, simultaneamente nas aulas de Português e de Espanhol Línguas Adicionais na UNILA e nas aulas de Espanhol Língua Estrangeira na UNIOESTE.

Acreditávamos, inicialmente, que a prática da aprendizagem em tandem permitiria aos nossos alunos e alunas um momento de reflexão sobre a própria aprendizagem, pois observando o processo de aprendizagem de seu/sua parceiro(a), e pensando na forma como estava auxiliando seu/sua companheiro(a) a aprender sua própria língua, esse(a) aluno(a) eventualmente desenvolveria uma maior consciência do processo de ensino-aprendizagem como um todo, assim como do próprio aprendizado, fato que lhe permitiria observar e entender o processo similar que acontece nas suas aulas de LE e, eventualmente, auxiliar o professor no alcance dos seus objetivos pessoais e das metas da turma. Essa abordagem teria, além dessa, muitas outras vantagens; entre elas, a grande riqueza das distintas contribuições: alunos diferentes trazem diferentes pontos de vista sobre os processos de aprendizagem e formas de otimizá-los.

O problema inicial, no entanto, estava vinculado a um outro ponto já debatido: embora o tandem focalizasse a avaliação como processo, os nossos alunos estavam acostumados com a avaliação somativa, fincada sobre o resultado 
e sobre a quantificação da aprendizagem, resumida a uma soma de erros e acertos linguísticos. Um caso ilustrativo dessa conjuntura ocorreu na primeira sessão realizada com as turmas de línguas da UNILA. Nos dez minutos finais da primeira sessão de tandem entre as turmas de ELA e PLA, os professores pediram que os alunos fizessem em conjunto uma avaliação da sessão, do seu desempenho e do desempenho do outro. No momento de avaliar o desempenho da parceira, um dos tandenistas simplesmente declarou: "Você foi muito bem, você tirou 9!". Obviamente, aproveitamos o momento para debater o que os alunos entendiam por "avaliação", as formas de avaliação com as quais estavam acostumados ou aquelas que acreditavam ser mais efetivas. Ao mesmo tempo, essa pequena anedota nos aclarou o caminho não tão simples que precisaríamos traçar para conseguir, de fato, realizar uma avaliação formativa com nossas turmas.

É interessante observar, neste momento, que mesmo após 2 meses de sessões semanais de tandem e de conversas reflexivas sobre avaliação, os alunos ainda definiram o momento de avaliação como sendo uma avaliação somativa. Em um questionário online, criado no googledocs, no qual poderiam permanecer anônimos, as respostas à questão "Para você, avaliação é:", podem ser visualizadas no gráfico abaixo:

\section{Para você, a avaliação é:}

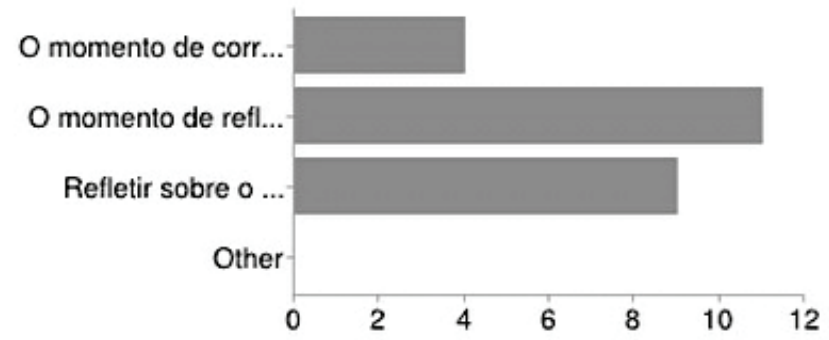

1. O momento de corrigir meu/minba parceiro(a) e baseado nos seus erros, dizer como ele se saiu na sessão: $4 / 24 \%$

2. O momento de refletir sobre os avanços do meu/minha parceiro(a), baseado nos encontros anteriores, e dizer como ele se saiu na sessão: 11 / 65\%

3. Refletir sobre o que meu/minha parceiro(a) ainda está errando e de pensar em soluções para isso: 9 / 53\%

Interessantemente, os mesmos alunos definiram a autoavaliação como uma avaliação formativa. Ao responderem à questão "Para você, autoavaliação é:", o resultado foi o seguinte: 


\section{Para você, autoavaliação é:}

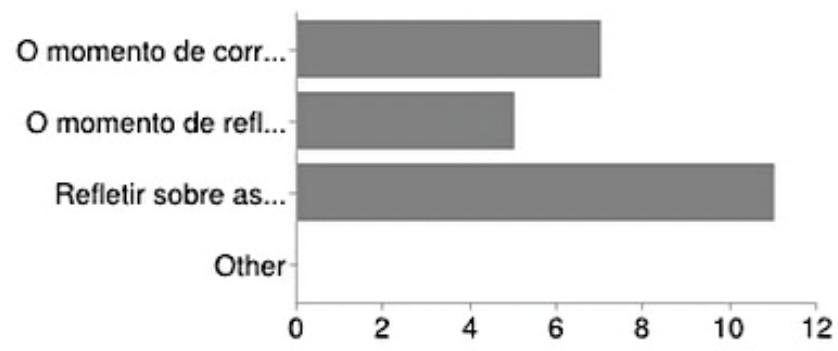

1. O momento de corrigir meus erros e pensar no que eu consegui aprender na sessão: 7 / $41 \%$

2. O momento de refletir sobre os meus avanços globais, baseado nos encontros anteriores, e dizer como eu me saí na sessão: 5 / 29\%

3. Refletir sobre as minhas dificuldades presentes e pensar em soluções para elas: $11 / 65 \%$

Antes de nos determos na análise dos dados, porém, vamos revisar a proposta inicial de pesquisa e o método empregado.

\section{PROPOSTA E MÉTODO}

\subsection{Proposta inicial}

Em resumo, a proposta inicial dessa pesquisa-ação consistia em levar nossos alunos a refletirem sobre a avaliação no processo do tandem e, ao mesmo tempo, verificarem a relevância e os efeitos dessa reflexão para seu comportamento e desempenho em sala de aula. Mais especificamente, decidimos nos deter na avaliação das competências orais, de produção, compreensão e interação, que, como já foi mencionado, consideramos mais desafiadoras.

\subsection{Metodologia}

Essa pesquisa foi desenvolvida, como já exposto, com diversas turmas de português e espanhol língua estrangeira/adicional. Na Universidade Federal da Integração Latino-Americana (UNILA), os alunos hispano-falantes que estavam 
aprendendo português tinham sessões de tandem presencial, i.e., face a face, com os alunos brasileiros que estavam em aula, aprendendo espanhol, no mesmo período. Na UNIOESTE, por outro lado, a turma de espanhol participou, em horário extra classe, de sessões de teletandem (através do Skype e de outros suportes digitais) com alunos de português do Centro de Enseñanza de Lenguas Extranjeras da Universidade Nacional Autônoma do México (CELE - UNAM). Os encontros aconteceram semanalmente e duravam de 1 a 2 horas.

A metodologia selecionada para a coleta e análise dos dados foi a participativa, apoiada em teorias críticas e em vertentes da fenomenologia, especialmente, como concebida dentro de uma pesquisa-ação. Tal método se mostrou interessante, pois prioriza o envolvimento de todos os atores ligados ao problema que se pretende resolver. Corrobora, portanto, a centralidade da interação aluno-professor buscada em nossas práticas, como se observa nas atividades do tandem. Assim, é a partir da

\footnotetext{
interação prolongada entre pesquisadores e atores [que] surgem novas construções de conhecimento voltadas para a prática. A partir de mapeamentos e sistematizações, tais construções tornam-se conhecimento apropriado pelos usuários e, ao mesmo tempo, validadas no plano científico pelos pesquisadores e profissionais. (THIOLLENT, 2007, p. 95)
}

São, de fato, os conhecimentos resultantes dessa construção que compartilhamos neste artigo. Como o autor acima mencionado, entendemos a pesquisa-ação como um método que permite a verificação de seus resultados no próprio transcorrer do projeto, resultados esses concebidos como formas de resolução dos problemas iniciais e daqueles que surgem ao longo do processo de investigação. Ao mesmo tempo, todo conhecimento assim produzido é validado pela própria experiência alcançada ao longo das atividades de pesquisa.

Dessa forma, paralelamente e com o objetivo de incrementar a efetividade da pesquisa, foi criado um banco de dados provenientes de Conversas Reflexivas (YONEMURA, 1982) realizadas no fim de cada sessões, com os pares, ou nas aulas subsequentes, com o grupo todo. Nessas conversas, convidamos os alunos a refletirem de maneira crítica sobre suas práticas de aprendizagem e sobre seu desenvolvimento oral na língua alvo. Tais diálogos têm a vantagem de guiar a ponderação sobre a avaliação, ao mesmo tempo em que permitem que o aluno vivencie na prática o que está sendo debatido na teoria: ou seja, ele aprende a pensar a avaliação, refletindo sobre a avaliação de seu próprio processo de aprendizado.

Finalmente, criamos (e aprimoramos ao longo do semestre, como resultado das conversas reflexivas) três tipos de questionários ou formulários. Dois questionários iniciais focavam na avaliação do colega e na autoavaliação, e eram 
utilizados pelos tandenistas no final de cada sessão de tandem. Esses questionários inicialmente tiveram a forma de uma grelha como a proposta por Furtoso (2011) - Imagem 1 - e, com o desenvolver das sessões, foram adaptados e culminaram nas formas observadas nas Imagens 2 e 3. Um terceiro questionário - Imagem 4 - foi criado para avaliar as concepções e crenças relacionadas à avaliação e à autoavaliação. Ele foi aplicado online no início e no final do semestre letivo.

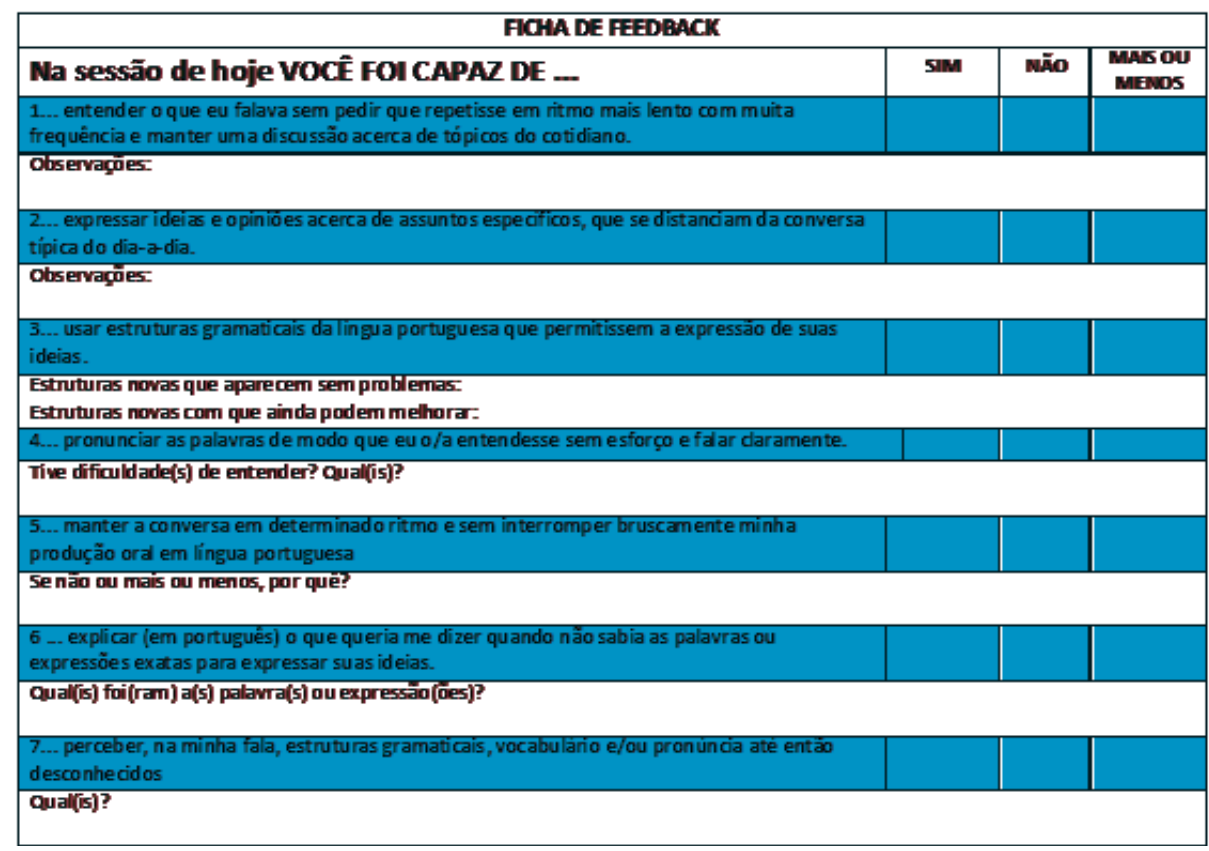

Imagem 1: Grelha de avaliação proposta por Furtoso (2011)

Com essa primeira ficha, o grande desafio se apresentou quando os alunos demonstraram associar os conceitos SIM, NÃO e MAIS ou MENOS com julgamentos de valor ou quantificações da aprendizagem, resultando em uma avaliação somativa focada, principalmente, na quantidade de erros do(a) colega. Nossa pesquisa eventualmente apontou que esse tipo de grade, de uma certa forma, se coloca ainda dentro de um método tradicional de avaliação de produtos, que classifica entre aptos a passar e não aptos. Para levar os alunos à desconstrução desse paradigma, optou-se, então, por um redirecionamento das conversas reflexivas em que as professoras faziam provocações e, com perguntas mais abertas, guiavam os aprendizes à reflexão e à avaliação de uma forma mais global. Além disso, como os 
alunos tiveram dificuldade em pensar sobre o processo de aprendizagem somente no final do encontro, nessas mesmas conversas reflexivas com os grupos, decidiu-se que seria mais produtivo incorporar essas fichas de avaliação no processo do tandem e chegou-se a "quadros de controle" para serem usados durante os encontros:

\section{REFLETINDO SOBRE MINHA APRENDIZAGEM...}

DATA:

NOMES:

TEMAS:

1. Hoje, eu compreendi tudo? Não tive problemas em entender o que meu/minha colega queria dizer?

2. Me senti mais SEGURO falando de/ tentando expressar: (alegria; opinião positiva; opinião negativa; concordância; desacordo; projetos; etc)

3. Me senti mais INSEGURO

falando de/tentando expressar:

(medo; dúvida; alegria; hipóteses; fatos no passado; projetos; et)

4. O que eu queria, mas não consegui falar/expressar?

(sentimentos; dúvida; teorias complexas/ abstratas; contrapor ideias; argumentar sem hesitar; etc)

5. Quando não consegui me expressar, qual foi minha reação? O que eu fiz?

(Mudei de assunto; Desenhei; Traduzi; Tentei explicar com outras palavras; Fiz mímica, gestos; etc)

6. O que eu percebi que aprendi? Notei que já aprendi algo que não sabia antes? O que? (falar do passado; expressar medo; concordar com emoção; negociar sentidos; etc)

Imagem 2: Fichas de controle abertas desenvolvidas nesse projeto 


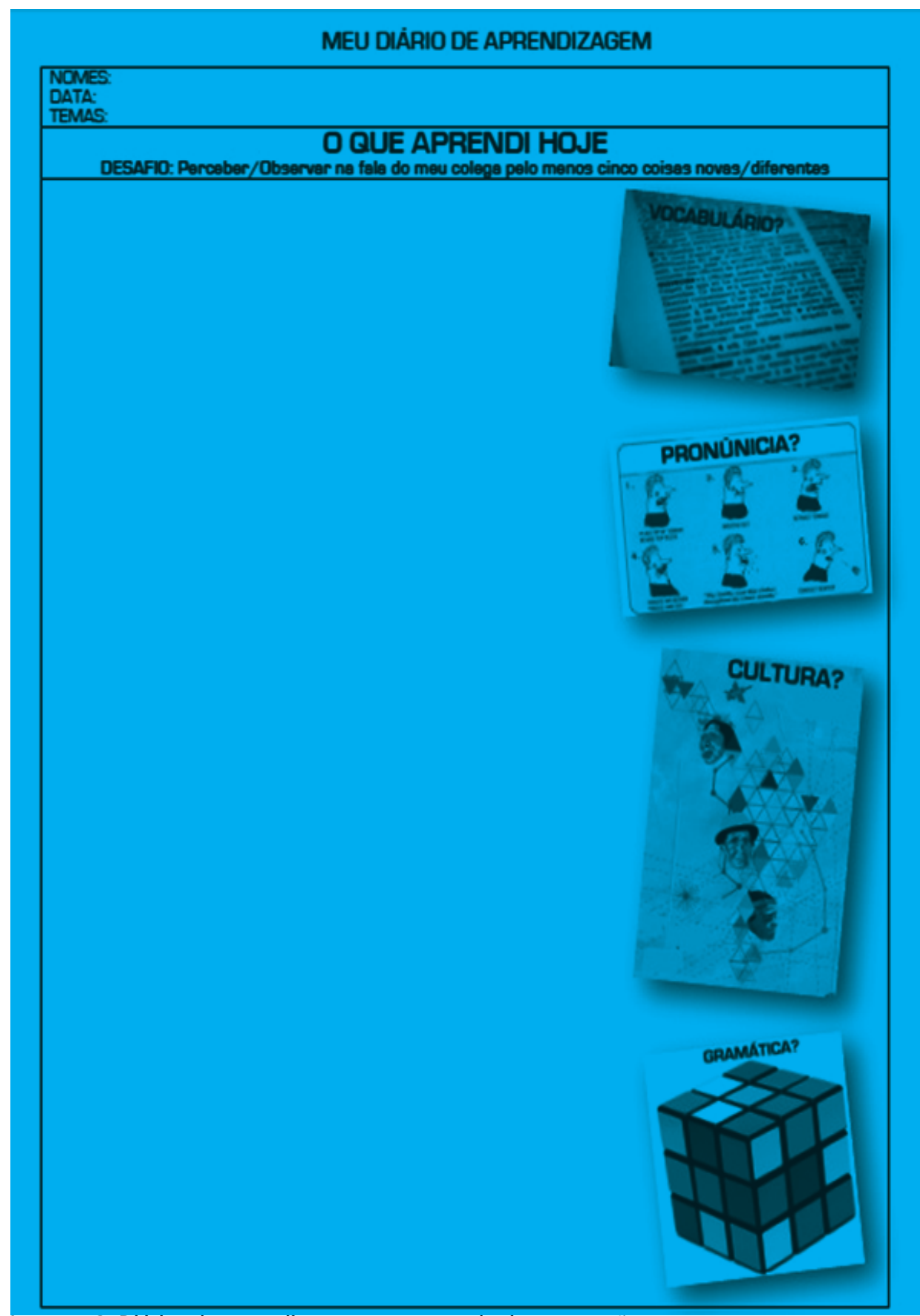

Imagem 3: Diários de aprendizagem para controle da progressão 


\section{AVALIAÇÃO NO TANDEM E DO TANDEM}

Questionário de avaliaçăo do tandem como recurso de aprendizagem de línguas autêntico e autônomo e dos processos de avaliação dentro dos encontros.

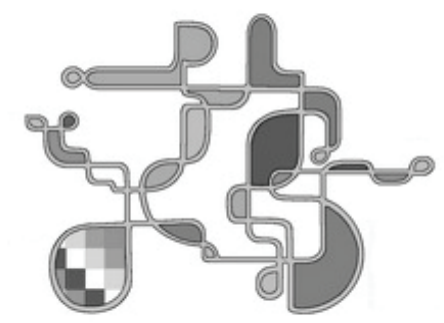

NOME:

Se vocẹ năo quiser se identificar, apenas escreva "anónimo".

ESTUDANTE DE:

Portuguès

Español

Faz tandem há quanto tempo?

1 a 4 semanas

4 a 8 semanas

8 a 12 semanas

Selecione, entre as opçōes abaixo, o seu nivel de satisfação com as atividades do tandem em suas aulas:

Muito alto

Alto

Médio

Baixo

Muito baixo

Continue *

$16 \%$ completed

Imagem 4: Questionário "AVALIAÇÃO DO TANDEM E NO TANDEM"

\section{PRIMEIROS RESULTADOS}

Analisando as respostas dos questionários e as anotações das conversas realizadas ao longo do semestre, foi possível concluir que, no nível micro, esse processo de avaliação e autoavaliação do aprendizado no tandem, incorporado nas aulas de línguas, permitiu que as práticas do tandem e de avaliação fossem sendo melhoradas/adequadas àquele contexto. No nível macro, fomentou maior 
participação dos aprendizes nas decisões da sala de aula. Acima de tudo, os aprendizes desenvolveram maior consciência de seu papel de agentes no processo global de ensino-aprendizado e de críticos do seu progresso.

$\mathrm{Na}$ turma da UNIOESTE, por exemplo, os estudantes que se propuseram a participar do tandem começaram a voltar-se com um olhar e comportamento diferentes nas aulas curriculares de LE, participando com mais afinco, interagindo e, consequentemente, se destacando e despertando o interesse e a curiosidade dos colegas que não estavam participando do projeto. Durante as aulas, tanto no curso de Letras como no curso de Hotelaria, os estudantes tandenistas comentaram que perceberam suas limitações, que notaram as circunstâncias em que não logram expressar-se e/ou produzir sentido na língua meta. Por conseguinte, esses alunos verbalizaram a necessidade de estudo e o desejo de ampliar o aprendizado para poderem comunicar-se melhor com o companheiro estrangeiro.

Voltando aos resultados dos questionários apresentados na Seção 4.3, podemos observar a persistência de uma conceitualização de avaliação e autoavaliação distintas. Quando estão pensando na evolução do próprio aprendizado, descobrimos que os alunos compreendem a (auto)avaliação de forma qualitativa, focalizando no seu potencial de balizar o aprendizado para melhorar as práticas posteriores em busca de seus objetivos. No que diz respeito à avaliação dos pares, contudo, persistiu a ideia de que a avaliação é uma atividade quantitativa, convindo para certificar um determinado nível/resultado do colega, focada no balanço dos erros e acertos daquele.

Tais resultados não são necessariamente incoerentes. De fato, acreditamos que tais respostas demonstram o nível de comprometimento do aluno com o processo de aprendizagem em questão. Ao pensar sobre seu aprendizado, seria possível concluir que os alunos desenvolveram sim a consciência de sua responsabilidade pelo próprio desempenho. Essa primeira prática, contudo, não foi suficiente para sensibilizar os alunos de sua responsabilidade para com a performance do colega.

Finalmente, ao examinarmos uma outra questão do mesmo questionário, podemos afirmar que a concepção geral sobre o que é avaliação e quais são seus fins foi modificada. Ao serem questionados, ao final de três meses de sessões, sobre a sua definição de avaliação, ou de como a avaliação deveria ser, ficou evidente a tomada de consciência dos aprendizes sobre a importância da avaliação formativa em sala de aula: 
Seguindo sua opinião, escolha a melhor definição de avaliação entre as duas abaixo. Faça isso levando em conta o ensino-aprendizagem de línguas em contextos formais, como a escola e a sala de aula:

A avaliação deve ser realizada por todos, constantemente, com o objetivo de revisar a prática e modificar constantemente os meios para se alcançar os objetivos do curso: $16 /$ $94 \%$
A avaliação deve ser realizada por um especialista que, baseado nos conteúdos do curso, classificará os rendimentos do aprendiz e definirá quem conseguiu alcançar os objetivos da aprendizagem: 1 $16 \%$

Tal mudança de conceito tem levado alunos e professores envolvidos nos projetos a reanalisarem seus papéis, o que promove uma maior participação dos alunos no processo de avaliação dos cursos de LE e, consequentemente, um maior aproveitamento do estudante. A título de exemplificação, durante uma avaliação de língua espanhola no Curso de Letras da UNIOESTE, a aluna tandenista foi a única a acertar as questões de análise contrastiva português/espanhol, no que concerne ao uso do presente do subjuntivo, posto que encontrava-se constantemente refletindo acerca das proximidades e diferenças entre as duas línguas no tandem. É válido ressaltar que a referida aluna manteve contato constante com sua companheira para além dos encontros semanais realizados na Universidade, o que nos permitiu acompanhar mais de perto o processo de aprendizagem das parceiras e perceber a evolução da discente no que concerne a sua produção oral em LE, autoconfiança e tomadas de decisão no decorrer das aulas.

\section{CONSIDERAÇÕES FINAIS}

À vista destas considerações, cremos ser possível declarar que o tandem, se integrado às práticas de sala de aula e monitorado por um(a) professor(a), pode ser uma ferramenta importante na sensibilização dos aprendizes a uma avaliação formativa e, consequentemente, a um aprendizado mais responsável e autônomo. 
É importante ressaltar, contudo, que esses resultados foram alcançados através de um trabalho intenso e constante. O que somente foi possível por meio de muitas conversas reflexivas com os aprendizes envolvidos, nas quais destacamos, como citado anteriormente, o papel central da comunicação e interação alunoprofessor.

Como colocado na nossa breve reflexão teórica acerca da autonomia na aprendizagem e da avaliação, verificamos que o tandem pode, de fato, ser um recurso poderoso na formação de um aprendiz mais consciente da importância de sua participação ativa no processo de ensino-aprendizagem; participação essa que passa, necessariamente, pela construção de um aprendiz ativo e comprometido com a avaliação formativa e com os processos de sala de aula.

Além disso, também verificamos a grande vantagem dessa ferramenta didática para a prática das habilidades orais em língua estrangeira ou adicional. A grande maioria dos alunos envolvidos demonstrou maior desenvoltura e domínio da língua em atividades orais de sala de aula, além de desenvolver uma maior confiança em sua performance nos momentos de interação em grupo.

Em 2015, os projetos seguem sendo implantados em ambas as Universidades, com um público diferente. Nesta fase, tentamos incorporar os resultados obtidos até o momento da escritura deste artigo (novas fichas, controles, questionários) desde o início das atividades. Esperamos, assim, poder otimizar o tempo investido para a sensibilização dos discentes à avaliação formativa e, consequentemente, para a construção de ambientes de ensino-aprendizagem mais participativos e potencializados.

\section{REFERÊNCIAS BIBLIOGRÁFICAS}

ARAUJO, N.R.P. (2012). Formação de parcerias de teletandem: Da organização ao sistema de atividades. Dissertação de Mestrado. UNESP - P.P.G. em Estudos Linguísticos. Orientadora: Dra. Solange Aranha.

BENEDETTI, A.M.; CONSOLO, D.A.; VIEIRA-ABRAHÃO, M.H. (2010). Pesquisas em Ensino e Aprendizagem no Teletandem Brasil: Linguas estrangeiras para todos. Campinas: Pontes Editores.

BENEDETTI. A.M. \& LUVIZARI-MURAD, L. (2013). Componentes e dinâmicas organizacionais de uma parceria para a aprendizagem de português e alemão via teletandem. In: Revista de Letras Norte@mentos - Revista de Estudos Linguísticos e Literários, Ed. 12 - Estudos Linguísticos. 
BLOOM, B. S. et al. (1971). Handbook on formative and summative evaluation of student learning. Nova York: McGraw-Hill Book Company.

BRAMMERTS, H; CALVERT, M. (2003). Learning by communicating in tandem. In: LEWIS, T.; WALKER, L. (Eds.) Autonomous Language Learning In-Tandem. Sheffield, UK: Academy Electronic Publications.

BRANDÃO, A. C. de L. (2011). Shall we dance? Colaboração e bistórias do processo de busca por parceiros de tandem. 184 f. Dissertação (Mestrado)-Universidade Federal de Uberlândia, Uberlândia.

BRINDLEY, G. (2001). Assessment. In: CARTER, R; NUNAN, D. The Cambridge guide to teaching English to speakers of other languages. Cambridge University Press.

CAVALARI, S.M.S. (2009). A auto-avaliação em um contexto de ensino-aprendizagem de línguas em tandem via chat. Tese de Doutorado. PPG em Estudos Linguísticos, UNESP-S.J. Rio Preto.

CHUEIRI, M. S. F. (2008). Concepções sobre avaliação escolar. In: Estudos em Avaliação Educacional, v. 19, p. 49 -64.

DA COSTA CARVALHO, D. \& SCHLATTER, M. (2011). Ações de difusão internacional da língua portuguesa. Cadernos do IL, n.42.

DA COSTA CARVALHO, D. (2012). Políticas de promoção internacional da língua portuguesa: ações na América Latina. In: Trabalbos em Linguística Aplicada, vol.51 no.2, Campinas Jul./Dec. 2012.

DA ROCHA, S. (2009). Ameliorer l'accompagnement dans les partenariats de teletandem francobresiliens. Master Arts, Lettres, Langues, Communication. Université Charles-de-Gaulle, Lille III, France.

DICKINS, P. R.; GERMAINE, K. (2014). Managing evaluation and innovation in language teaching: Building bridges. Nova York: Routledge.

DICKINSON, L. (1987) Self-instruction in Language Learning. Cambridge: Cambridge University Press.

DICKINSON, L. (1994). Learner Autonomy: what, why and how? In: LEFFA, V. J. (Org.). Autonomy in Language Learning. Porto Alegre: Editora da UFRGS.

DE CARVALHO FIDELIS BRAGA, J. (2004). Aprendizagem de línguas em regime de tandem via e-mail: colaboração, autonomia e estratégias sociais e de compensação. Dissertação de Mestrado. Faculdade de Letras da UFMG. Belo Horizonte.

DE CASTILHO, A.T. (2010). Uma política lingü.stica para o português. In: Textos do Museu da Língua Portuguesa, publicado em 13/10/2010. Disponível em: http://www. museulinguaportuguesa.org.br/files/mlp/texto 17.pdf Acesso em: 15 de abril de 2015.

DE SOUZA, O. (2001). Abordagens fenomenológico-hermenêuticas em pesquisas educacionais. Revista Contrapontos, v. 1, n. 1. 2001, p. 31-38.

DEMO, P. (1996). Avaliação sob olhar propedêutico. Campinas: Papirus. 
DO NASCIMENTO, A.M. (2014). Interculturalidade: apontamentos conceituais e alternativa para a educação bilíngue. In Revista SURES, n. 3, 2014. Disponível em: https://ojs.unila.edu.br/ojs/index.php/sures/article/view/121. Acesso em: 20 de fevereiro de 2015.

DUARTE, P. A. P. (2013). Oespanbol no Brasil: "problemas eperspectivas". Trabalho de Conclusão de Curso (Graduação em Letras - com habilitação em língua espanhola) - Universidade Estadual da Paraíba, Campina.

FERNANDES, D. (2006). Para uma teoria da avaliação formativa. Revista Portuguesa de Educação, 19 (2), pp.21-50. CIEd - Universidade do Minho.

FERNANDES, D. (2008). Para uma teoria da avaliação no domínio das aprendizagens. Etudos em Avaliação Educacional v.19, n. 41.

FREIRE, P. (1996) Pedagogia da Autonomia: Saberes necessários à prática educativa. 21 ed. Rio de Janeiro: Paz e Terra.

FURTOSO, V.A.B. (2011). Desempenbo oral em português para falantes de outras línguas: da avaliação à aprendizagem de linguas estrangeiras em contexto online. Tese de Doutorado. P.P.G. em Estudos Linguísticos, UNESPS.J.R.P.

GARCIA, D.N.M. (2013). O Que os Pares de Teletandem (Não) Negociam. São Paulo: Editora UNESP.

GONÇALVES, S.C.L et al. (2011). A ordem SV/VS no português em aquisição como L2 na fronteira Brasil/Paraguai: uma investigação sociofuncionalista na interface aquisição/variação. Guavira Letras, p. 61.

GUIMARÃES, F.I.S. (2011). Aquisição do português como L2 por falantes de espanbol: uma experiência com o modelo de ontogenia. 2011. Tese de Doutorado. Universidade de São Paulo.

HOLEC, H. (1981). Autonomy and foreign language learning. Oxford: Pergamon Press.

KAMI, C.M.C. (2011). A motivação na aprendizagem de língua estrangeira via teletandem. Dissertação de Mestrado. UNESP, P.P.G. em Estudos Linguísticos.

KIPPER, E. (2013). Aquisição de segunda língua em contextos de bilinguismo societal. Letrônica: Revista Digital do PPGL, v. 5, n. 3, p. 88-102.

LAIA, Fernanda Maria Marques. (2010). Expressão oral em Francês Lingua Estrangeira: concepção $e$ análise de instrumentos de avaliação. Dissertação de Mestrado. Universidade Aberta, P.P.G. em Estudos Francófonos.

LEFFA, V. J. (2003). Quando menos é mais: a autonomia na aprendizagem de línguas. In: NICOLAIDES, Christine; MOZZILLO et al. (Orgs.). O desenvolvimento da autonomia no ambiente de aprendizagem de línguas estrangeiras. Pelotas: UFPEL.

LITTLE, D. (1996). La compétence stratégique examinée par rapport à la maîtrise stratégique du processus d'apprentissage des langues. In: Holec, Little \& Richterich, Strategies in language learning and use : studies towards a common European framework of reference for language learning and teaching. Strasbourg: Council of European Publishing, p. 9-40.

LITTLE, D. (1991). Learner autonomy I: Definitions, issues and problems. Dublin: Authentik, 1991. 
LOPES DA SILVA, A. (2013). A auto-regulação da aprendizagem: estudos teóricos e empíricos. InterMeio:: Revista do Programa de Pós-Graduação em Educação-UFMS, v. 10, n. 19

LOURENÇO, R. J. D. S. P. (2012). Transferência na aquisição de línguas próximas: expressões idiomáticas. Dissertação de Mestrado. Universidade de Aveiro.

MESQUITA, A.A.F. (2008). Crenças e práticas de avaliação no processo interativo e na mediação de um par no tandem a distância: um estudo de caso. Dissertação de Mestrado. P.P.G. em Estudos Linguísticos. UNESP-S.J.R.P.

OTSUKA, J. L.; ROCHA, H. V. (2002). Avaliação Formativa em Ambientes de EaD. In: XIII Simpósio Brasileiro de Informática na Educação (SBIE 2002). São Leopoldo, 12-14 de novembro.

PACHECO, José Augusto. (2012). Avaliação das aprendizagens: políticas formativas e práticas sumativas. In: Encontros de Educação, Funchal, 10 e 11 de fevereiro de 2012. Encontros. Funchal: Secretaria da Educação do Governo Regional da Madeira.

PAIVA, V.L.M.O. (2005). Autonomia e complexidade: uma análise de narrativas de aprendizagem. In: Freire, M.M; Abrahão, M.H.V; Barcelos, A.M.F (Orgs.). Linguística Aplicada e Contemporaneidade. Campinas e São Paulo: Pontes e ALAB, 2, 2005, p.135153.

PERRENOUD, P; THURLER, M. G. (2002). As competências para ensinar no século XXI: a formação dos professores e o desafio da avaliação. Porto Alegre. Artmed.

RAMALHO AGUIAR, A.L. \& SANTOS DE ALBUQUERQUE, F.D. (2014). Projeto de extensão língua portuguesa para a UNILA: a integração pelo ensino de Português como Língua Estrangeira. In: Revista SURES, n. 3.

RAMMÉ, V. (2014). Tandem: guia pra uma aprendizagem solidária = TANDEM: guía para un aprendizage solidario. Curitiba: Valdilena Rammé.

RAMMÉ. V. (2015). TANDEM: pedalando juntos em espanhol e português/TANDÉM: pedaleando juntos en español y portugues. Experiência. Revista Científica deExtensão, v.1, p. 83-93.

ROLIM, A.C.O. (1998). A cultura de avaliar de professores de lingua estrangeira (Inglês) no contexto da escola pública. Dissertação de mestrado. UNICAMP, Campinas.

RUANO, B. P. (2012). O Método tandem como sistema de aprendizado autônomo de língua estrangeira. Dissertação de Mestrado. Universidade Federal do Paraná.

SANTINI, F. \& SZYMANSKI, H. (2010). O método fenomenológico-hermenêutico na investigação de práticas educativas parentais. Anais IV SIPEQ, 2010. Disponível em: http://www.sepq.org.br/IVsipeq/anais/index.html. Acesso em: 15 de abril de 2015.

SANTOS, J. F. S. S. (2006). Avaliação do Ensino a Distância. In: Revista Iberoamericana de Educación, n. 38/4.

SCARAMUCCI, M.V.R. (1999). Avaliação: mecanismo propulsor de mudanças no ensino/ aprendizagem de língua estrangeira. Contexturas, v. 4.

SILVA-OYAMA, A. C. (2010). Communication strategies for Portuguese/Spanish learning in-teletandem. Revista Brasileira de Linguística Aplicada, v. 10, n. 1, p. 89-112. 
SOUZA, M.G. (2012). Os primeiros contatos de professores de linguas estrangeiras com a prática de teletandem. Dissertação de Mestrado. UNESP, P.P.G. em Estudos Linguísticos, 2012.

TELLES, J.A.; MAROTI, F.A. (2008). Teletandem: Crenças e respostas dos alunos. In: PINHO, S.Z. e SAGLIETTI, J.R.O.C. NÚCLEOS DE ENSINO DA UNESP: Artigos dos projetos realizados em 2006. São Paulo: Cultura Acadêmica Editora.

TELLES, J. A. \& VASSALLO, M.L. (2006). Foreign language learning in-tandem: Teletandem as an alternative proposal in CALLT. The ESPecialist, v. 27(2). PUC-SP, 2006, p. 189-212.

THIOLLENT, M. \& SILVA, G.O. (2007). Metodologia de pesquisa-ação na área de gestão de problemas ambientais. RECIIS - R. Eletr. de Com. Inf. Inov. Saúde. Rio de Janeiro, v.1, n.1, p.93-100, jan.-jun.

VASSALLO, M.L. \& TELLES, J. A. (2006). Foreign language learning in-tandem: Theoretical principles and research perspectives. The ESPecialist, v. 27(1), Brasil, PUCSP, 2006, p. $83-118$.

VEIGA SIMÃO, A.M. (2004). Integrar os princípios da aprendizagem estratégica no processo formativo dos professores. A. Silva, A. Duarte, I. Sá, \& A. Veiga-Simão, Aprendizagem auto-regulada pelo estudante. Perspectivas psicológicas e educacionais, p. 95 117.

VICENTE, G.C.B. (2014). A Interferência da Língua Materna na Aprendizagem de uma Língua Estrangeira. UNOPAR Científica Ciências Humanas e Educação, v. 10, n. 1.

YONEMURA, M. (1982). Teacher conversations: A potential source of their own professional growth. In Curriculum Inquiry, p. 239-256. Ontario: John Wiley \& Sons.

ZAMBRANO, L. (2013). Intercambios fronterizos, metamorfosis del espacio y desplazamiento lingüistico, in Revista SURES, n. 1.

ZOPPI-FONTANA, M.G. \& DINIZ, L.R.A. (2008). Declinando a língua pelas injunções do mercado: institucionalização do português língua estrangeira (PLE), in Estudos Lingüisticos, São Paulo, v. 37, n. 3, p. 89-119.

Recebido: 29/07/2015

Aceito: 14/10/2015 